\title{
ASSESSING STRATEGIC KNOWLEDGE MANAGEMENT PRACTICES AT THE INSTITUTION OF INDUSTRIAL DEVELOPMENT AND RESEARCH- THE MINISTRY OF IRAQI INDUSTRY (IDRMII)
}

\author{
Fatimaalaaalddineubayd, Atheer Abdullah Mohammed \\ University of Baghdad, College of Administration and Economics,wasit, Iraq
}

DOI: $10.37648 / \mathrm{ijrssh} . v 10 \mathrm{i} 03.019$

Received: $08^{\text {th }}$ June, 2020; Accepted:20 $0^{\text {th }}$ June, 2020; Published: $13^{\text {th }}$ July,2020

\begin{abstract}
The key research objective of this study is to asses strategic knowledge management practices in its dimensions (making strategic meaning. exploring strategic knowledge. sharing strategic knowledge. and investing strategic knowledge) at the macro level (its administrative units) and individual (human resources) in the Industrial Research and Development Authority / Ministry of Industry and Minerals. Hence.finding appropriate and optimal methods for managing these practices.The present research is designed according to the descriptive method. To achieve the main goal of the above research.the researchers used the questionnaire as a main tool to collect data by polling the opinions of a sample of managers at the upper and middle management level and the questionnaire was distributed to an intentional sample from the managers of the upper and middle departments working in the Industrial Research and Development Authority within the job categories (general manager. assistant director General. department heads. center heads. official and people) and numbered 150.and a number of statistical techniques were used within the programs (AMOS.V25, SPSS.V21) for the purposes of processing the collected data and reaching the results.This study reached a set of results.the most important of which is the interest of the Industrial Research and Development Authority in managing strategic knowledge. especially when investing knowledge after exploring it and making strategic meaning and sharing it in that interest.The focus on the one institution represented by the research and development organization / the single ministry of industry and within the one environment and (the industrial environment) is one of the most prominent determinants of this study.as it is difficult to generalize practical results to other workplace environmentsand sectors. Checking the extent of interest in strategic knowledge management practices.represented in the need to increase awareness and awareness of senior administrative leaders and decision makers in industrial organizations of the importance of management concepts for the current study and related to the vital role of strategic knowledge management.The research was drawn from a master thesis that was not discussed.Authenticity / valueThis research
\end{abstract}


represents a modest addition to the Iraqi academic storage in the field of management science and organizational behavior studies and human resources on assessing the level of strategic knowledge management practices.

Key words: strategic knowledge management practices.

\section{INTRODUCTION}

The need has emerged to adopt contemporary management concepts.including the management of strategic knowledge of the organization.to reflect this concept of the outcome of the interaction between many fields of knowledge and science.The most prominent characteristic of strategic knowledge management is its ability to provide successful solutions to most of the problems or obstacles that hinder the functioning of the organization.The most prominent characteristic of strategic knowledge management is its ability to provide successful solutions to most of the problems or obstacles that hinder the functioning of the organization.Therefore.strategic knowledge management contributes to drawing strategies and plans.which in turn leads to high quality products that meet the desires and needs of customers.obtain a greater market share and increase the organization's profits.This creates a mental image and a wide reputation for customers.as organizations put strategic knowledge management for the purpose of shaping the future for them.and in this light.human.financial and technological resources must be allocated.Therefore.organizations in general should prepare for that future and draw their strategic direction logically.

Over the past ten years.there have been theoretical and field studies that focused on the vital role of strategic knowledge management in determining the future of the organization. And based on the recommendations of some relevant intellectual propositions and previous practical studies and the lack of our local industrial environment for such research and studies.this research came to take the lead in studying the evaluation of the level of strategic knowledge management practices in the Research and Development Authority of the Ministry of Industry and Minerals as the organization responsible for the development of our industrial organizations.

The research problem: The current research problem is embodied through the initial visits of the researcher to the Industrial Research and Development Authority affiliated to the Ministry of Industry and Minerals and revealed the extent of the need by the industrial sector for strategic administrative practices related to knowledge.The main problem lies in the extent to which these organizations benefit from the practices of managing strategic knowledge in its dimensions, The main problem lies in the extent to which these organizations benefit from the practices of managing strategic knowledge in its dimensions.Therefore.the research problem arises by answering the following basic question: (What is the level of focus of the research organization. the Industrial Research and Development Authority / Ministry of Industry and Minerals on strategic knowledge management practices(Making strategic meaning, exploring strategic knowledge, sharing strategic knowledge, and investing strategic knowledge)?

research importance: 1 . Theoretical side: The research deals with one of the most important contemporary and vital issues in administrative thought for all types of organizations.including industrial ones, which is strategic knowledge management practices.given the vital role that knowledge plays in the organization at the macro level

2. The practical side: A-This research contributes to increasing the awareness and awareness of senior administrative leaders and decision-makers in the research organization of the importance of administrative concepts of the current research and related to the vital role of strategic knowledge management practices.

B- The importance of the current research is highlighted in his choice of the industrial sector, which is an essential tributary of the tributaries of development and the advancement of the economic reality of the country.as the results of its success will be reflected on all active economic sectors.especially with regard to industrial projects.

research aims:Evaluates the extent of interest in strategic knowledge management practices in its 
dimensions (making strategic meaning, exploring strategic knowledge, sharing strategic knowledge, and investing strategic knowledge)At the macro level (its administrative units) and the individual (its human resources) in the Industrial Research and Development Authority / Ministry of Industry and Minerals, and then reaching appropriate and optimal methods for managing these practices.

Research community and sample:Research Society: It is represented by the Industrial Research and Development Authority located in Baghdad / AlJadriyah region as a site for conducting research as the responsible authority in the Ministry of Industry and Minerals, which means scientific research and industrial development(Preparing research plans and following up their implementation) in their research centers and in the industrial research and development departments of the Ministry's companies and in various scientific and industrial specialties, The current research community was represented by managers at the upper and middle administrative levels of (278) people, due to the nature of the research that requires a degree of understanding and awareness in dealing with the questionnaire questions.In addition, these occupational groups are responsible for making strategic decisions for the organization, and strategic knowledge management practices and distinct performance indicators (research variables).Its importance emerges with a large percentage within these administrative levels as variables focusing on strategic aspects, and on this basis the research sample was intentional (intentional).

The research sample: The sample included (general manager, assistant general manager, department heads, heads of centers, official and people).

Strategic Knowledge Management:Knowledge is one of the primary resources for strategic management by helping administrators understand the basic characteristics of a company and maintaining its competitive position. The organization creates knowledge and then effectively uses it to create competitive advantages (Shih et al, 2018: 1).In recent years, knowledge management has appeared in the business world not only as an important aspect of doing business but also as a strategic source that increases the capabilities of institutions to achieve a competitive
advantage.Successful managers realize that the value of their organizations has become more reliable through the company's ability to effectively manage knowledge (Novak, 2017: 434).The essence of knowledge management is to provide strategies to make enterprise knowledge available to those who need them in order to improve human and organizational performance (Alhamaudi, 2010: 33).For the purpose of properly managing knowledge, strategic knowledge management must be formulated (Mohajan, 8: 2017). Knowledge management needs to relate to business strategy to focus on distinct knowledge-based competencies (resources, capabilities) and full use of knowledgebased capabilities from a strategic perspective (Cabrilo, 2018: 2-7).Integrating strategic knowledge management into the organization's strategy is a truism, as it is an effective way to achieve the desired results, as it represents a high-level strategic plan by defining processes and tools in addition to the organizational infrastructure and technology required to be prepared (Zahir, 2014: 181).Existing literature indicates that different knowledge management efforts are useless if they are not clearly linked to organizational strategy. Strategic knowledge management is important for any type of organization.The concept of strategic knowledge management has received the attention of researchers' studies in various fields as a description of newly emerging concepts, as several studies have emerged for these studies which are somewhat close to each other as they have known it (Theriou et al, 2011: 109).It is the process of generating, coding and transferring knowledge within the organization and getting the right information to the right person at the right time and place. The organization's strategy defines the needs, means and activities necessary to achieve the goal.(Kianto and Andreeva, 2014: 223) was defined as the ability to identify, create, change, transfer, integrate and apply the superior knowledge resource available in individuals or organizations that include a wide range of activities and interactions to improve and innovate new.

\section{The importance of strategic knowledge management:}

1. Strategic Knowledge Management improves the competitive advantage of the organization and 
provides long-term benefits through administrative support (Kor, 2013: 294).

2. Strategic knowledge management is an effective way to analyze the environment in order to identify and develop specialized strategies and that knowledge is one of the primary resources for strategic management by helping administrators to understand the fundamental characteristics of the organization and maintain its competitive position (Minglu et al, 2018: 1)

3. Strategic Knowledge Management allows the organization to focus on departments that innovate more, stimulate creativity and continuous innovation for its members and also help in problem solving, strategic planning and decisionmaking, thus improving the results of creativity and performance (Cabrilo, 2018: 8).

4. Organized strategic knowledge management practices help in developing and increasing creativity and services and introducing new, differentiated, innovative products (Maroofi, 2012: 29).

5. Given the strategic role that knowledge management plays as an essential organizational resource, organization management has given exceptional importance in focusing on supporting research and knowledge studies to maintain survival and adapt to rapid technological and environmental changes in today's world (Tabatabaei, 2015: 448).

6. Strategic Knowledge Management helps organizations greatly in building sound customer relationships that greatly influence customer satisfaction and overall performance (Zaied, 2012: 2).

7. This administration contributes to enhancing the organization's ability to maintain and improve organizational performance based on experience and knowledge (Mahdi, 2012: 262).

\section{Strategic knowledge management practices:}

1. The strategic meaning industry:The strategic meaning of knowledge comes from employee experiences and skills using different methods and facts to develop and restructure current and past knowledge.Any organization can create new facts and meanings. Scientific indicators for the knowledge industry include: the importance of the value of the knowledge industry and the existence of an appropriate mechanism to convert implicit knowledge into explicit knowledge and the level of use of external knowledge and encourage the organization to create knowledge and reward and encourage employees to innovate and bring new ideas and continuous talk about the experiences and failures of the organization (Nouri, 2017: 196).This process includes creating new knowledge in the organization through multiple activities such as research and development, process design, investment and learning, in addition to that, the organization seeks according to this process to obtain knowledge from various external and internal sources and that the process of obtaining knowledge includes the organization's ability to extract information and ideas from the external environment And the interior, and there are four common methods that organizations use to obtain knowledge are (Al-Azzawi, 2011: 255):Individual learning,Environmentalsurvey,Experience ,Obtaining knowledge from workers in other organizations.

2. Explore strategic knowledge:The literature on strategic knowledge management refers to several definitions related to the practice of exploring strategic knowledge, some of them focused on innovation processes based on the internal resources of the organization.Others referred to external resources, including both of them together, and the following are some of these definitions, the practice of knowledge exploration can be defined as the close relationship between the knowledge of the organization and its 
capacity for innovation and creativity as exploration works to a large extent through the exchange of knowledge and this exchange allows the development of innovation from During his focus on tacit knowledge (Nicola, 2011: 504).This practice includes the process of exploring and learning appropriate knowledge from various internal and external resources such as experiences, related documents, plans, etc.This practice was known as the process of exploring appropriate knowledge from various internal and external resources such as interviews, experiences, documents, plans, mapping, monitoring, learning and training, and this is considered one of the most important techniques for exploring knowledge.It is understood from this that information gathering will bring knowledge to the organization either by generating new knowledge through internal sources such as daily experiences or employee experience or accessing valuable knowledge from external information sources and other organizations (Riungu, 2015: 17).

3. Distribute strategic knowledge:The practice of sharing strategic knowledge is an important component of the success of strategic knowledge management and directly affects other knowledge processes related to exchange, publishing, sharing and sharing (Al-Faris, 2010: 71).The knowledge sharing process helps people exchange implicit and explicit knowledge and generate new knowledge between people.The basis for the work of knowledge sharing is that it shares knowledge, exchanges and collects scattered knowledge to foster innovation and creativity, which ultimately leads to achieving gains that will achieve outstanding organizational performance.It is also considered an important component for the success of knowledge management and is necessary for the proper use of knowledge assetsIt also directly affects other knowledge processes such as the integration of knowledge and its manufacture and is the basis for the manufacture and generation of new knowledge and indicates the process by which individuals share experiences and information with each other and thus increase the resources of the organization and reduce time loss in trial and error (Abualoush, 2018: 284-289).

4. Investing strategic knowledge:The practice of investing strategic knowledge is one of the prominent practices in the strategic management of knowledge in view of the prominent role it plays in the processes of creativity, storage and distribution to improve performance as it does the process of effective application of knowledge, especially in the strategic process and in achieving high quality products and services to meet the needs of customers and as a result, knowledge becomes a strength And a fortune in that one if you invest correctly (Bouzidawi and Mohamed, 32: 2014). Generating, storing and distributing knowledge is absurd procedures if they are not used effectively, that is, finding meaning for the information received and applying it to workers either directly or through the organization and organization of the organization.

* Workers should know that they have the information to improve customer service and product quality

* Employees are able to find meaning in the information they receive

* For workers to be free to invest their knowledge

\section{The practical side:}

First: Description and diagnosis of the influencing variable of strategic knowledge management practices:The independent variable influencing strategic knowledge management practices is measured by four dimensions (making strategic meaning, exploring strategic knowledge, sharing strategic knowledge, investing strategic knowledge) in the form 
of industrial research and development, as it represents the dimension of twenty paragraphs, distributed equally across every five Paragraphs according to scale (Theriou et al., 2011: 109),Descriptive statistical analysis has summarized the dimensions of strategic knowledge management practices as follows:

Industry strategic meaning:The results of the descriptive statistics of the independent dimension data showed the making of the strategic meaning of having the machinery and the methods by which it links the impact of decisions and their understanding and their ability to identify errors, awareness and identification of success steps and its critical factors, as well as the impact of those decisions, behaviors and various adjustments, so the dimension got a weighted arithmetic mean (3.49 Available, exercising with an average level of interest $(69.8 \%)$, with a relative difference coefficient $(20.4 \%)$ and with a standard deviation (0.713) which indicates agreement, homogeneity and convergence in the level of sample responses on that availability, interest and practice, as shown in the results of Table (1).As for the level of the paragraphs in which the dimension was measured in the Industrial Research and Development Authority, paragraph (5) (The Authority provides training programs for its employees on how to distinguish between accurate, reliable, inaccurate and reliable information sources) arranging with a relative difference factor $(24.6 \%)$ and with relative interest (73.6) \%) Average, while the fifth and last arrangement of paragraph (4) (there is flexibility in taking and amending decisions in the event of new strategic information appearing) with a relative difference factor $(28.9 \%)$ and relative interest $(67.8 \%)$ acceptable, while the other paragraphs showed the work of the Authority's management on Transforming it into a knowledge society in light of the accelerating change in its work environment, as well as its constant emphasis on avoiding repetition of previous mistakes regarding the implementation of its strategic decisions, as it takes into account all the visions and proposals put forward as a nurturing for decision-makers regarding the possession of strategic knowledge when senior management meets with middle and supervisory departments .

Table (1) Analysis and Diagnosis of the Independent Dimension Industry Strategic Meaning $(\mathbf{n}=123)$

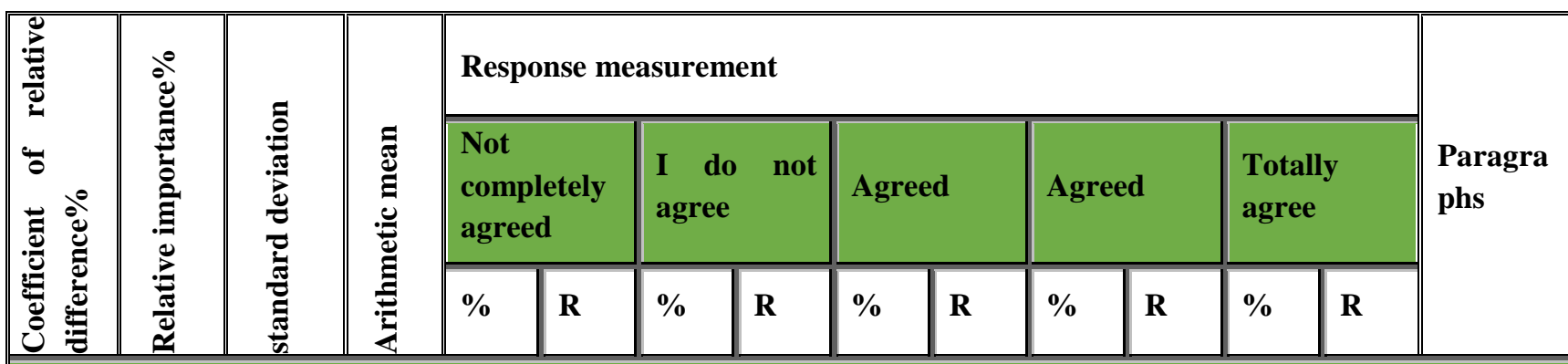

Senior management is working to transform the body into a knowledge society adapted to the rapid change in the environment

\begin{tabular}{|l|l|l|l|l|l|l|l|l|l|l|l|l|l|l|l|}
\hline 25.2 & 70.6 & .890 & 3.53 & 1.6 & 2 & 12.2 & 15 & 27.6 & 34 & 48.8 & 60 & 9.8 & 12 & 1 \\
\hline \hline
\end{tabular}

Senior management takes into account all the visions and proposals put forward regarding strategic knowledge when meeting with the middle and supervisory departments

\begin{tabular}{|l|l|l|l|l|l|l|l|l|l|l|l|l|l|l|}
\hline \hline 26.6 & 67.8 & .902 & 3.39 & 0 & 0 & 21.1 & 26 & 26 & 32 & 45.5 & 56 & 7.3 & 9 & 2 \\
\hline \hline
\end{tabular}

It is ensured by senior management to avoid repeating mistakes in the implementation of strategic decisions

\begin{tabular}{|l|l|l|l|l|l|l|l|l|l|l|l|l|l|l|}
\hline 25.5 & 69.6 & .889 & 3.48 & 0.8 & 1 & 16.3 & 20 & 26 & 32 & 48 & 59 & 8.9 & 11 & 3 \\
\hline \hline
\end{tabular}

There is flexibility in making and adjusting decisions if new strategic information appears 


\begin{tabular}{|c|c|c|c|c|c|c|c|c|c|c|c|c|c|c|}
\hline 28.9 & 67.8 & .980 & 3.39 & 2.4 & 3 & 18.7 & 23 & 26 & 32 & 43.1 & 53 & 9.8 & 12 & 4 \\
\hline \multicolumn{15}{|c|}{$\begin{array}{l}\text { The Authority provides training programs for its employees on how to distinguish between accurate, reliable, } \\
\text { inaccurate and reliable information sources }\end{array}$} \\
\hline 24.6 & 73.6 & .908 & 3.68 & 4.9 & 6 & 4.1 & 5 & 20.3 & 25 & 59.3 & 73 & 11.4 & 14 & 5 \\
\hline$\underline{20.4}$ & $\underline{69.8}$ & .713 & $\underline{3.49}$ & \multicolumn{11}{|c|}{ Industry strategic meaning } \\
\hline
\end{tabular}

2.Explore strategic knowledge:Table (2) shows that, after exploring strategic knowledge, a weighted (3.50) arithmetic mean is available and practiced with a relative level of interest $(70 \%)$ average through the Authority's industrial research and development process of exploring the new knowledge represented by obtaining data and information, and synthesizing previous knowledge in order to find opportunities New work appears outside the scope of its current strategy, which contributes to enhancing the continuity of its activities and activities in the long run. The dimension obtained a coefficient of relative difference (21\%) and a standard deviation (0.736) indicating convergence and homogeneity in the level of sample responses about the dimension. The results of the descriptive statistical analysis showed that paragraph (7) (the organization understands the variables and directives in its work sector) has a relative difference coefficient $(24.4 \%)$ and a relative interest $(70.6 \%)$ average to be in the first rank in terms of the level of agreement on the availability, practice and adoption of the body from the point of view Consider the sample, while the fifth arrangement of paragraph (10) (the organization is interested in gathering new information that leads us to learn new ideas and innovations) with a factor of relative difference $(29.4 \%)$ and relative interest $(70.8 \%)$ is average, and by returning to the other three paragraphs the results showed the knowledge of the organization Through her periodic meeting with the departments on the trends and developments in their target markets, as well as her focus on gaining knowledge about the strategies involved in high risks, while she has a complete vision about the technology of modern industry in the world.

Table (2) Analysis and Diagnosis of the Independent Dimension Exploring Strategic Knowledge $(\mathbf{n}=123)$

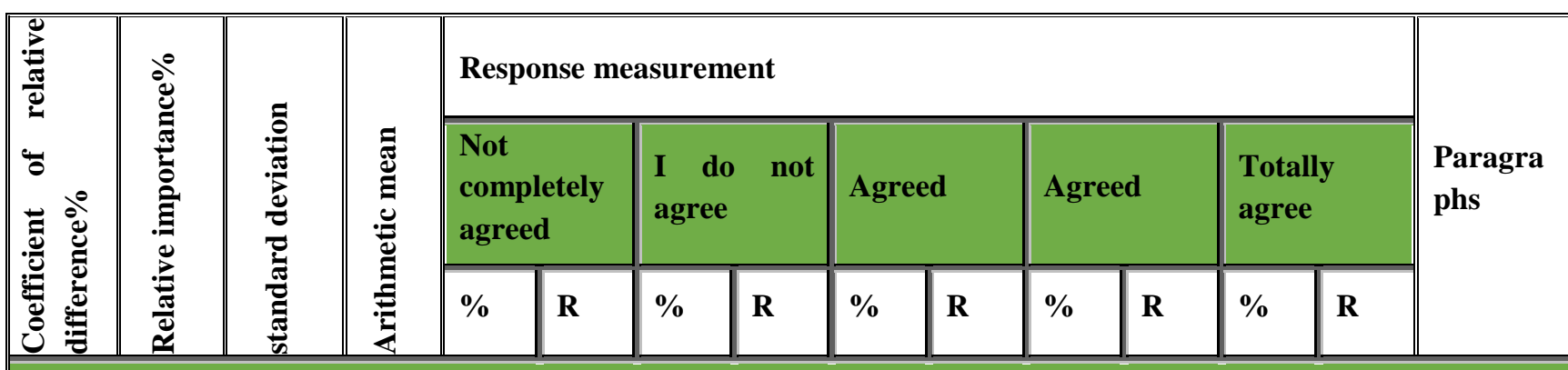

The Authority has a complete vision of modern industrial technology in the world

\begin{tabular}{|l|l|l|l|l|l|l|l|l|l|l|l|l|l|l|l|}
\hline \hline 27.9 & 70 & .978 & 3.50 & 6.5 & 8 & 4.9 & 6 & 30.9 & 38 & 47.2 & 58 & 10.6 & 13 & $\mathbf{6}$ \\
\hline \hline
\end{tabular}

The Commission understands the changes and directives in its sector

\begin{tabular}{|l|l|l|l|l|l|l|l|l|l|l|l|l|l|l|l|}
\hline \hline 24.4 & 70.6 & .862 & 3.53 & 3.3 & 4 & 8.1 & 10 & 27.6 & 34 & 54.5 & 67 & 6.5 & 8 & 7 \\
\hline \hline
\end{tabular}

Through regular meetings with the departments, the Authority looks forward to the trends and developments in the market

\begin{tabular}{|l|l|l|l|l|l|l|l|l|l|l|l|l|l|l|l||}
\hline \hline 24.7 & 72.2 & .892 & 3.61 & 1.6 & 2 & 10.6 & 13 & 25.2 & 31 & 50.4 & 62 & 12.2 & 15 & $\mathbf{8}$ & \\
\hline \hline
\end{tabular}

Focuses on gaining knowledge about high-risk strategies 


\begin{tabular}{|l|l|l|l|l|l|l|l|l|l|l|l|l|l|l|l|}
\hline 26.7 & 66.4 & .889 & 3.32 & 3.3 & 4 & 13 & 16 & 38.2 & 47 & 39.8 & 49 & 5.7 & 7 & 9 \\
\hline
\end{tabular}

The organization is interested in collecting new information that leads us to learn new ideas and innovations

\begin{tabular}{|c|c|c|c|c|c|c|c|c|c|c|c|c|c|c|}
\hline 29.4 & 70.8 & 1.042 & 3.54 & 5.7 & 7 & 13 & 16 & 14.6 & 18 & 55.3 & 68 & 11.4 & 14 & 10 \\
\hline 21 & 70 & .736 & 3.50 & & & & & & & & & & & \\
\hline
\end{tabular}

3. Share strategic knowledge:The independent dimension got the sharing of strategic knowledge on a weighted arithmetic mean (3.46) available, and exercises a relative interest (69.2\%) average through the tendency of the Industrial Research and Development Authority to share the knowledge gained through its individual and organizational levels, through dialogue interactions and brainstorming sessions between its members and its internal divisions Through finding formal and informal communication channels, this knowledge will be the strategic basis for the starting point of its work, so the dimension at the general level obtained a standard deviation (0.650) indicating agreement, coherence and convergence in the level of answers about the availability of the dimension and its practice with a relative difference factor (18.7\%), and as Show the results of Table (3).

From the results of descriptive statistics, as in table (12), paragraph (11) (members of senior management share their ideas during the meetings to discuss developing the environment) on the first order with a relative difference factor $(22.3 \%)$ and practice at a level of interest (72.2\%) medium, while the fifth arrangement was Paragraph (15) (information of strategic importance in the organization is more easily accessible to those who need it more) with a factor of relative difference $(29.7 \%)$ and relative interest (66.2\%) acceptable, while other paragraphs have received relative interest $(70 \%$ $67.2 \%)$ from the acceptable average and by a factor A relative difference $(27.7 \%-23.5 \%)$ about the Authority's interest in disseminating data on customer satisfaction at all organizational levels and according to the rules and procedures of its work, as important information, both positive and negative about its competitive environment, reaches decision-makers quickly and according to its importance to other departments.

Table (3) Independent Dimension Analysis and Diagnostics Strategic Knowledge Sharing (n= 123)

\begin{tabular}{|c|c|c|c|c|c|c|c|c|c|c|c|c|c|c|}
\hline \multirow{3}{*}{ 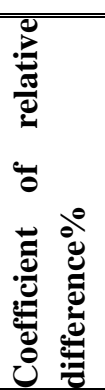 } & \multirow{3}{*}{ 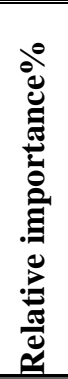 } & \multirow{3}{*}{ 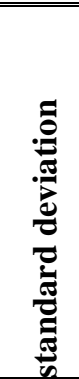 } & \multirow{3}{*}{ 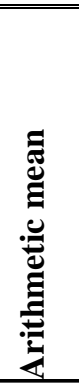 } & \multicolumn{10}{|c|}{ Response measurement } & \multirow{3}{*}{$\begin{array}{l}\text { Paragra } \\
\text { phs }\end{array}$} \\
\hline & & & & \multicolumn{2}{|c|}{$\begin{array}{l}\text { Not } \\
\text { completely } \\
\text { agreed }\end{array}$} & \multicolumn{2}{|c|}{$\begin{array}{l}\text { I do not } \\
\text { agree }\end{array}$} & \multicolumn{2}{|c|}{ Agreed } & \multicolumn{2}{|c|}{ Agreed } & \multicolumn{2}{|c|}{$\begin{array}{l}\text { Totally } \\
\text { agree }\end{array}$} & \\
\hline & & & & $\%$ & $\mathbf{R}$ & $\%$ & $\mathbf{R}$ & $\%$ & $\mathbf{R}$ & $\%$ & $\mathbf{R}$ & $\%$ & $\mathbf{R}$ & \\
\hline \multicolumn{15}{|c|}{ Senior management members share their thoughts during the meetings to discuss environmental development } \\
\hline 22.3 & 72.2 & .806 & 3.61 & 1.6 & 2 & 8.1 & 10 & 25.2 & 31 & 57.7 & 71 & 7.3 & 9 & 11 \\
\hline \multicolumn{15}{|c|}{$\begin{array}{l}\text { Data on customer satisfaction are published at all organizational levels according to the organization's rules and } \\
\text { procedures }\end{array}$} \\
\hline 23.5 & 67.2 & .790 & 3.36 & 0.8 & 1 & 12.2 & 15 & 42.3 & 52 & 39.8 & 49 & 4.9 & 6 & 12 \\
\hline
\end{tabular}

The information is published quickly according to its importance to other departments 


\begin{tabular}{|l|l|l|l|l|l|l|l|l|l|l|l|l|l|l|l|}
\hline 27.7 & 70 & .971 & 3.50 & 1.6 & 2 & 14.6 & 18 & 25.2 & 31 & 48.8 & 60 & 9.8 & 12 & $\mathbf{1 3}$ \\
\hline
\end{tabular}

Important, even bad information about a competitive environment quickly reaches decision-makers

\begin{tabular}{|l|l|l|l|l|l|l|l|l|l|l|l|l|l|l|l|}
\hline \hline 25.4 & 70 & .890 & 3.50 & 0.8 & 1 & 11.4 & 14 & 38.2 & 47 & 36.6 & 45 & 13 & 16 & $\mathbf{1 4}$ \\
\hline
\end{tabular}

Information of strategic importance is readily available to those who need it most

\begin{tabular}{|l|l|l|l|l|l|l|l|l|l|l|l|l|l|l||}
\hline \hline 29.7 & 66.2 & .984 & 3.31 & 4.9 & 6 & 14.6 & 18 & 33.3 & 41 & 39 & 48 & 8.1 & 10 & $\mathbf{1 5}$ \\
\hline \hline 18.7 & 69.2 & .650 & 3.46 & \multicolumn{6}{|l||}{ Share strategic knowledge } \\
\hline
\end{tabular}

4.Investing strategic knowledge:The research sample showed a relative agreement (78.9\%) on the authority's possession of industrial research and development, the ability to manage knowledge and use it to achieve a competitive advantage, as well as work to formulate effective strategies and find dynamics to adapt through it to its environment, as Table (4) shows that the independent dimension is an investment Knowledge of a relative difference coefficient (21.1\%), on the relative interest of the organization in practicing the dimension and its adoption (70.8\%) on the average, and a standard deviation (0.728) at the general level to indicate agreement and homogeneity in its views on that interest and availability in an arithmetic mean (3.54).

While paragraph (16) (strategic knowledge is used to improve products and services), it obtained the first rank with a coefficient of relative difference $(21.8 \%)$, and with relative interest in practice and adoption (74\%) average, while the fifth ranking of paragraph (19) (senior management of the organization is taken With interest, the suggestions submitted by the working groups on how to use strategic knowledge efficiently and effectively) with a relative difference coefficient $(27.4 \%)$, with relative interest $(69.2 \%)$ average, while the other three paragraphs got a relative difference coefficient $(26 \%-23.5 \%)$ and with a level of relative interest $(71.8 \%-68.8 \%)$ is acceptable to the average in allocating strategic knowledge to control its strategic direction, as its use of strategic knowledge in its various activities leads to creating instances of creativity and innovation of effective methods and working methods, which leads the body to better invest in this knowledge in improving efficiency Its internal operations.

Table (4) Analysis and Diagnosis of the Independent Dimension Investment of Strategic Knowledge $(\mathbf{n}=123)$

\begin{tabular}{|c|c|c|c|c|c|c|c|c|c|c|c|c|c|c|}
\hline 焉 & $\partial^{0}$ & & & $\operatorname{Re}$ & nse $n$ & asur & ent & & & & & & & \\
\hline 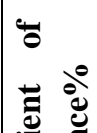 & 彦 & & 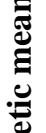 & $\begin{array}{l}\text { No } \\
\text { con } \\
\text { agr }\end{array}$ & etely & $\begin{array}{l}\text { I } \\
\text { agI }\end{array}$ & not & Agl & & Ag & & $\begin{array}{l}\text { To } \\
\text { agI }\end{array}$ & & $\begin{array}{l}\text { Paragra } \\
\text { phs }\end{array}$ \\
\hline نِّ & $\frac{\pi}{0}$ & 竎 & 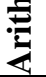 & $\%$ & $\mathbf{R}$ & $\%$ & $\mathbf{R}$ & $\%$ & $\mathbf{R}$ & $\%$ & $\mathbf{R}$ & $\%$ & $\mathbf{R}$ & \\
\hline
\end{tabular}

Strategic knowledge is used to improve products and services

\begin{tabular}{|l|l|l|l|l|l|l|l|l|l|l|l|l|l|l|l|l|}
\hline \hline 21.8 & 74 & .809 & 3.70 & 1.6 & 2 & 5.7 & 7 & 25.2 & 31 & 56.1 & 69 & 11.4 & 14 & $\mathbf{1 6}$ \\
\hline \hline
\end{tabular}

Strategic knowledge is devoted to controlling the strategic direction of the organization

\begin{tabular}{|l|l|l|l|l|l|l|l|l|l|l|l|l|l|l|l|}
\hline \hline 23.5 & 70.8 & .832 & 3.54 & 1.6 & 2 & 8.9 & 11 & 31.7 & 39 & 49.6 & 61 & 8.1 & 10 & 17 \\
\hline \hline
\end{tabular}

Employing strategic knowledge in different areas of performance leads to more effective innovations and methods 


\begin{tabular}{|l|l|l|l|l|l|l|l|l|l|l|l|l|l|l|}
\hline 24.1 & 71.8 & .866 & 3.59 & 2.4 & 3 & 8.1 & 10 & 26.8 & 33 & 52.8 & 65 & 9.8 & 12 & $\mathbf{1 8}$ \\
\hline \hline
\end{tabular}

The supreme management of the organization is taken into consideration the suggestions submitted by the working groups on how to use strategic knowledge efficiently and effectively

\begin{tabular}{|l|l|l|l|l|l|l|l|l|l|l|l|l|l|l|l||}
\hline \hline 27.4 & 69.2 & .951 & 3.46 & 4.1 & 5 & 13 & 16 & 23.6 & 29 & 52 & 64 & 7.3 & 9 & $\mathbf{1 9}$ \\
\hline
\end{tabular}

Strategic knowledge is invested in improving the efficiency of internal operations

\begin{tabular}{|l|l|l|l|l|l|l|l|l|l|l|l|l|l|l||}
\hline \hline 26 & 68.8 & .897 & 3.44 & 4.1 & 5 & 8.1 & 10 & 35 & 43 & 45.5 & 56 & 7.3 & 9 & $\mathbf{2 0}$ \\
\hline \hline 21.1 & 70.8 & .728 & 3.54 & \multicolumn{6}{|c||}{ Investing strategic knowledge } \\
\hline
\end{tabular}

From the researcher's review of the previous tables $(1,2,3,4)$, the organization's practice finds industrial research and development to share strategic knowledge in the first order, as a result of having the dimension get the lowest coefficient of relative difference $(18.7 \%)$, then followed by the industry making the strategic meaning with a different coefficient (20.4\%), Exploring strategic knowledge with a relative difference coefficient $(21 \%)$, and in the fourth and final order investing strategic knowledge, as the researcher notes that the four dimensions have been provided with a weighted arithmetic mean, practice, interest, and relative adoption that ranged from medium to acceptable.

The availability of the four dimensions (sharing strategic knowledge, making strategic meaning, exploring strategic knowledge, and investing strategic knowledge), respectively, has led to the availability of the variable Strategic Knowledge Management Practices with an arithmetic mean (3.50) available, and exercising with relative interest (70\%) through owning The Industrial Research and Development Authority is a futuristic vision about the core competencies and core capabilities that it possesses in light of the continuous environmental complexity, as well as obtaining the correct information and communicating it to the leaders at the appropriate time and place and defining the needs, means and activities necessary that it considers the basis of adaptation and flexibility needed to achieve the goals of the organization, while he indicated The relative difference coefficient (17.6\%) and the standard deviation (0.618) indicate the existence of agreement and homogeneity in the opinions of the research sample on the availability, practice and interest of the organization in the variable strategic knowledge management practices, as shown in the results of table (5)

Table (5): Arranging data for strategic knowledge management practices according to the relative difference coefficient

\begin{tabular}{|c|c|c|c|c|c|}
\hline Variables & $\begin{array}{l}\text { Relative } \\
\text { importance }\end{array}$ & $\begin{array}{l}\text { Coefficient of } \\
\text { variation }\end{array}$ & $\begin{array}{l}\text { standard } \\
\text { deviation }\end{array}$ & Arithmetic mean & Arrangement \\
\hline $\begin{array}{l}\text { Industry strategic } \\
\text { meaning }\end{array}$ & $69.8 \%$ & $20.4 \%$ & 0.713 & 3.49 & The second \\
\hline $\begin{array}{l}\text { Explore strategic } \\
\text { knowledge }\end{array}$ & $70 \%$ & $21 \%$ & 0.736 & 3.50 & the third \\
\hline $\begin{array}{l}\text { Share strategic } \\
\text { knowledge }\end{array}$ & $69.2 \%$ & $18.7 \%$ & 0.650 & 3.46 & the first \\
\hline $\begin{array}{l}\text { Investing strategic } \\
\text { knowledge }\end{array}$ & $70.8 \%$ & $21.1 \%$ & 0.728 & 3.54 & the fourth \\
\hline
\end{tabular}




\begin{tabular}{|l|l|l|l|l|l|}
\hline $\begin{array}{l}\text { Strategic } \\
\text { Knowledge } \\
\text { Management }\end{array}$ & $70 \%$ & $17.6 \%$ & 0.618 & 3.50 & \\
\hline
\end{tabular}

\section{CONCLUSIONS:}

Through the results of the descriptive statistics, it became clear to us that the priorities and concerns of the elite and middle departments (research sample) about strategic knowledge management practices in the research and development organization are represented by (using strategic knowledge, exploring strategic knowledge, making strategic meaning, sharing strategic knowledge) respectively and practicing Relative interest and adoption ranged from middle to acceptable.

1. Although it is issued after (the use of strategic knowledge) practices of strategic knowledge management and is represented prominently through the use of knowledge in improving products and services, the interest of the research sample is relatively less in the use of knowledge about how to improve internal processes and suggestions submitted by working individuals, and we conclude from this with Some limitations by the authority's leaders on these important parts of the practice of using strategic knowledge.

2. And it appeared after (Exploring Strategic Knowledge) in the second place, and the interest of the Industrial Research and Development Authority showed an acceptable interest in periodic meetings with departments for the purpose of knowing the directions and developments in the market, but it avoids focusing on acquiring knowledge of strategies that involve high risks.

3. It was found that after (the strategic meaning industry) ranked third, and this indicates a lack of adequate attention required by the higher and middle departments, as despite the agreement of the research sample and a good percentage on the presence of a clear interest by the Industrial Research and Development Authority to provide training programs that relate to excellence Among the sources of accurate and reliable information, however, the attention of the organization is less apparent about the emergence of any new strategic information, and this indicates that there is insufficient flexibility in making and modifying decisions by the decision-makers in the researched organization.

4. It became clear to us that after (the sharing of strategic knowledge) in the fourth and final rank, this shows that the Industrial Research and Development Authority does not give sufficient importance for the purpose of facilitating the arrival of information of strategic importance to the people who need it most, and it is also evident that its interest in sharing data on customer satisfaction at all organizational levels has become clear. And where its focus is on the participation of members of the senior management in their ideas through meetings to discuss developing the environment,

\section{RECOMMENDATIONS:}

1. The Industrial Research and Development Authority should use strategic knowledge more accurately and employ it fully through:

- Paying attention to the proposals submitted by their owners and making them reverse, through which knowledge strategies are developed in each of the joints of their implementation and formulation and the selection of appropriate alternatives.

- Using strategic knowledge and incorporating it into a new work style that develops from its current performance as well as looking at it on the basis of improved work methods and methods of implementation for overall performance and methods that encourage creativity and innovation 
- Employing strategic knowledge as an additional dimension of the strategic direction of the organization, and that forms the basis for other dimensions.

2. The Industrial Research and Development Authority should give more attention to exploring strategic knowledge through:

- Attention to collecting information in the field of specialization and classifying it in a database in order to learn new ideas and benefit from them for inputs to new knowledge processes that can be used if necessary.

- Seeing modern technology in the field of industry and working to benefit from it and simulating theexperiences of successful organizations in the field of developing their technology.

- Examine the risks in detail before adopting the strategies by looking at their advantages and disadvantages before adopting the final image.

- Find an environmental analysis unit that is interested in studying changes in the body's environment in light of opportunities, threats, strength and weakness, and their contribution to activating knowledge strategies aimed at bringing about a change in the organization's performance.

3. The Industrial Research and Development Authority should pay extra attention to making its strategic meaning through:

- Giving the decision-maker the additional flexibility in a way that is compatible with facilitating the workprocedures and directives of the organization without harming its goals, regulations and laws.

- Taking into consideration all proposals and opinions by employees of the lower administrative groups from a participatory perspective that contributes to improving the level of performance of the organization.

- Study the visions, proposals and strategic options with great care and in a manner compatible with the capabilities and capabilities of the organization in light of economic feasibility and alternative opportunities.

- Keeping pace with the change in the cognitive environment and the transition to scientific research methods and employing its tools in ways to develop the organization's long-term performance.

4. It is necessary to give the Industrial Research and Development Authority the additional attention in sharing the knowledge of its members and transforming the tacit knowledge into an explicit knowledge transmitted between its members, units and departments by facilitating access to information by adopting methods of storing, retrieving and sharing that knowledge and information by adopting strategic information systems that are accessible to leaders and continuously fed From various sources in the style (360)

\section{SOURCES:}

1. The assistant teacher, Samira Ahmed Mahdi. (2012). Knowledge management processes and their impact on creative capabilities. Journal of the Baghdad College of University Economics, (30), 255-280.

2. Bouzidzi, Mohamed, (2014), Knowledge Management as a Basis for Achieving Sustainable and Distinguished Performance, Case Study of Xian University, Master Thesis in Management Sciences, Faculty of Economic Sciences, Commercial Sciences and Management Sciences, University of Algeria.

3. Abualoush, S., Masa'deh, R. E., Bataineh, K., \&Alrowwad, A. (2018). The role of knowledge management process and intellectual capital as intermediary variables between knowledge management infrastructure and organization performance. Interdisciplinary Journal of Information, Knowledge, and Management, 13, 279-309.

4. Cabrilo, S., \&Dahms, S. (2018). How strategic knowledge management drives intellectual capital to superior innovation and market performance. Journal of Knowledge Management.

5. Kianto, A., \&Andreeva, T. (2014). Knowledge management practices and results in service-oriented versus product-oriented companies. Knowledge and Process Management, 21(4), 221-230.

6. Kör, B., \&Maden, C. (2013). The relationship between knowledge management and innovation in Turkish service and high-tech firms. International Journal of Business and Social Science, 4(4). 
7. López-Nicolás, C., \&Meroño-Cerdán, Á. L. (2011). Strategic knowledge management, innovation and performance. International journal of information management, 31(6), 502-509.

8. Maroofi, F. (2015). Strategic Knowledge Management, Innovation, and Performance. In Encyclopedia of Information Science and Technology, Third Edition (pp. 4709-4719). IGI Global.

9. Mohajan, H. (2017). The roles of knowledge management for the development of organizations.

10. Nouri, B. A., Ghorbani, R., \&Soltani, M. (2017). The effect of knowledge management on organizational innovation with the mediating role of organizational learning (case study: Agricultural Bank in Iran). Journal of Applied Economics and Business Research JAEBR, 7(3), 194-211.

11. Novak, A. (2017). Knowledge management and organizational performance-Literature review. In Management Challenges in a Network Economy: MakeLearn and TIIM International Conference.

12. Shih, D. H., Lu, C. M., Lee, C. H., Parng, Y. J. M., Wu, K. J., \& Tseng, M. L. (2018). A Strategic Knowledge Management Approach to Circular Agribusiness. Sustainability, 10(7), 2389.

13. Tabatabaei, S., Aqdam, B., Mehrzadegan, E., \&Kheiri, N. (2015). The role of knowledge management practices in development of innovative performance of organization. International Journal of Economics, Commerce and Management, 3 (6), 447-460.

14. Theriou, N., Maditinos, D., \&Theriou, G. (2011). Knowledge management enabler factors and firm performance: An empirical research of the Greek medium and large firms, European Research Studies Journal, Vol.14, No. 2, P.P. 97-13.

15. Zahir, ZainabHiawi, (2013), Adopting a knowledge management strategy and its role in achieving educational quality standards, an analytical study of the views of a sample of university teaching, Master of Science in Business Administration, College of Administration and Economics / University of Baghdad.

16. Zaied, A. N. H., Hussein, G. S., \& Hassan, M. M. (2012). The role of knowledge management in enhancing organizational performance. International Journal of Information Engineering and Electronic Business, 4(5), 27. 